\title{
BMJ Open A population-based observational study of diabetes during pregnancy in Victoria, Australia, 1999-2008
}

\author{
Marian Abouzeid, ${ }^{1,2}$ Vincent L Versace, ${ }^{1}$ Edward D Janus, ${ }^{1,3}$ Mary-Ann Davey, ${ }^{4,5}$ \\ Benjamin Philpot, ${ }^{1}$ Jeremy Oats, ${ }^{4,6}$ James A Dunbar ${ }^{1}$
}

To cite: Abouzeid M,

Versace VL, Janus ED, et al.

A population-based

observational study of

diabetes during pregnancy in

Victoria, Australia, 1999-

2008. BMJ Open 2014;4:

e005394. doi:10.1136/

bmjopen-2014-005394

- Prepublication history and additional material is available. To view please visit the journal (http://dx.doi.org/ 10.1136/bmjopen-2014005394).

Some findings from these data were presented as a poster at the 6th International Symposium on Diabetes and Pregnancy conference in Salzburg, Austria in March 2011.

Received 3 April 2014 Revised 22 September 2014 Accepted 22 October 2014

CrossMark

For numbered affiliations see end of article.

Correspondence to Professor James Dunbar; director@greaterhealth.org

\section{ABSTRACT}

Objectives: This paper reports secular trends in diabetes in pregnancy in Victoria, Australia and examines the effect of including or excluding women with pre-existing diabetes on gestational diabetes (GDM) prevalence estimates.

Design: Population-based observational study. Setting: All births in Victoria, Australia between 1999 and 2008

Participants: 634932 pregnancies resulting in a birth registered with the Victorian Perinatal Data Collection

Outcome measures: Crude and age-standardised secular trends in pre-existing diabetes and GDM prevalence; secular GDM trends by maternal birthplace; effects on GDM prevalence of including and excluding pre-existing diabetes from the denominator.

Results: Of the 634932 pregnancies, 2954 (0.5\%) occurred in women with pre-existing diabetes and 29147 (4.6\%) were complicated by GDM. Mean maternal age increased from 29.7 years in 1999 to 30.8 years in 2008. GDM prevalence increased in most maternal age groups. In 2008, age-standardised GDM prevalence was $31 \%$ higher than in 1999; secular increases were greater for Australian-born nonIndigenous (29\% increase) than immigrant women (12.3\% increase). The annual number of pregnancies in women with pre-existing diabetes almost doubled from 1999 to 2008 and prevalence increased from $0.4 \%$ to $0.6 \%$. However, including or excluding pre-existing diabetes had little effect on GDM prevalence estimates.

Conclusions: Pre-existing diabetes and GDM prevalence increased in Victoria between 1999 and 2008 and rising maternal age does not fully explain these trends. These findings have important implications for preventive initiatives. Including or excluding small numbers of women with pre-existing diabetes resulted in minimal changes in GDM estimates. As pre-existing diabetes in young women increases, this methodological issue will likely become important.

\section{INTRODUCTION}

True pregnancy-induced hyperglycaemia differs from pre-existing maternal diabetes. Pregnancy is diabetogenic: insulin resistance

\section{Strengths and limitations of this study}

- This study reports secular trends in Australian population-level prevalence of pre-existing diabetes in pregnancy and gestational diabetes (GDM) using data collected over 10 years from a comprehensive perinatal database that captures virtually all births in the state. Recording of GDM and pre-existing diabetes in this database have been shown to be highly accurate.

- This paper also examines an important epidemiological issue of the effect of including or excluding the growing group of women with pre-existing diabetes on GDM prevalence estimates. This methodological consideration is likely to become increasingly important as the number of women with pre-existing diabetes increases.

- As this study uses population-level administrative data it is not possible to identify unscreened pregnancies and screening practice may have changed over time.

increases with advancing gestation. Maternal insulin secretion normally increases in response; if insufficient to overcome the insulin resistance, hyperglycaemia occurs. Pre-pregnancy glycemic control is usually restored after delivery. ${ }^{1}$ This differs from preexisting maternal type 1 and type 2 diabetes, which are neither induced by pregnancy nor resolve post-partum. Any form of diabetes in pregnancy increases risk of a range of adverse maternal and neonatal outcomes; risk of some such complications is greater with pre-existing diabetes. ${ }^{2}{ }^{3}$ Moreover, preexisting maternal diabetes in pregnancy presents particular management issues. ${ }^{4}$

By definition, gestational diabetes mellitus (GDM) describes glucose intolerance that begins or is first recognised during pregnancy. ${ }^{5}$ Therefore, GDM encompasses both true pregnancy-induced hyperglycaemia and diabetes predating pregnancy but previously undiagnosed. Pre-existing diabetes is confirmed if postpartum testing demonstrates 
persistent dysglycaemia fulfilling non-pregnancy diagnostic thresholds for diabetes. ${ }^{6}$ However, antenatal records and birth reports, commonly used to ascertain GDM prevalence, are completed before these tests are conducted and their results known.

Prevalence of diagnosed pre-existing diabetes among pregnant women is generally increasing. ${ }^{3}{ }^{7-12}$ Recent secular increases in GDM burden have also been documented in Manitoba ${ }^{13}$ and Ontario, Canada, ${ }^{11}$ Tianjin, China ${ }^{14}$ and Bahrain. ${ }^{15}$ From across the USA there are reports of increasing GDM, ${ }^{9}{ }^{12} 1617$ increases followed by a levelling off, ${ }^{18}$ no temporal changes ${ }^{7}$ and fluctuations in disease burden over time. ${ }^{19}$ In Australia, over recent decades rising GDM burden has been reported $;^{320-23}$ trends in diabetes in pregnancy among Indigenous Australian women are inconsistent. ${ }^{10} 2024-26$

There are several methodological issues surrounding GDM epidemiology, including denominator selection. ${ }^{27}$ For example, Australian GDM studies have included in the denominator all pregnant women/births/confinements, ${ }^{2} 3102024-2628$ only singleton pregnancies, ${ }^{29} 30$ only screened/tested pregnancies, ${ }^{22}{ }^{31}$ excluded women with pre-existing diabetes ${ }^{23} 30$ and/or reported prevalence of all forms of diabetes in pregnancy collectively. ${ }^{10} 2426$ Similar methodological variation exists internationally.

The International Association of Diabetes and Pregnancy Study Group (IADPSG) recognises the issues associated with including women with pre-existing diabetes together with those with 'true' GDM. ${ }^{32} \mathrm{New}$ IADPSG recommendations advise that all or high-risk women without known glucose abnormalities undergo fasting plasma glucose (FPG), random plasma glucose or glycated haemoglobin A1c (HbA1c) testing at the first antenatal visit. This is to identify 'overt' diabetes (FPG $\geq 7.0 \mathrm{mmol} / \mathrm{L}$ or $\mathrm{HbAlc} \geq 6.5 \%$ or random plasma glucose $\geq 11.1 \mathrm{mmol} / \mathrm{L}$ and confirmed with FPG or HbA1c result) and early-onset GDM. ${ }^{32}$ The Australasian Diabetes in Pregnancy Society (ADIPS) recommends that high-risk women have a $75 \mathrm{~g}$ oral glucose tolerance test (OGTT) as soon as possible after conception to detect GDM. ${ }^{6}$ Both authorities recommend universal testing of remaining women using OGTT at 24-28 weeks to identify additional cases. ${ }^{62}$ The FPG level considered diagnostic of GDM will be reduced from $\geq 5.5$ to $\geq 5.1 \mathrm{mmol} / \mathrm{L}$, and the $2 \mathrm{~h}$ plasma glucose threshold is to increase from $\geq 8.0$ to $\geq 8.5 \mathrm{mmol} / \mathrm{L}$. ${ }^{6}$ These guidelines are expected to substantially increase the number of women diagnosed with GDM. ${ }^{33}$ The IADPSG and ADIPSG diagnostic criteria recommend dispensing with the Glucose Challenge Test (GCT). The GCT misses 25\% of GDM cases and consequently adoption of this step alone is likely to be a significant contributor to the increased diagnostic rates of GDM. ${ }^{34}$ The IADPSG recommendations are also intended to increase detection of pre-existing diabetes. As diagnosed pre-existing diabetes rises, the methodology used to calculate GDM prevalence may influence the estimates due to differing denominator sizes, particularly among ethnic groups and in settings where pre-existing diabetes prevalence is high. Such variation has a range of potential implications, including for funding and health service planning.

No recent population-level Australian studies examine longitudinal trends in pre-existing maternal diabetes, ${ }^{3}$ and few report recent trends in burden of GDM overall $^{20} 23$ or among various migrant groups. ${ }^{20}$ Using data routinely collected over 10 years from the state of Victoria, Australia, we investigated first, secular trends in prevalence of pre-existing diabetes in pregnancy; second, trends in GDM burden; and finally, the effects of including and excluding women with pre-existing diabetes on GDM prevalence estimates.

\section{METHODS}

The Victorian Perinatal Data Collection (VPDC) is a population-based surveillance system, maintained by the Consultative Council on Obstetric and Paediatric Mortality and Morbidity, Victorian Department of Health. Information is routinely collected on all births of at least 20 weeks' gestation (or if gestation is not known, birthweight of at least $400 \mathrm{~g}$ ). Birth report forms are completed at delivery by a clinician; notification of births to the VPDC by hospitals, birthing centres and private midwife practitioners is mandatory. Therefore, the database is considered to completely capture virtually all births in Victoria that fulfil reporting requirements.

De-identified data were extracted for all notified births that occurred in Victoria between 1 January 1999 and 31 December 2008. For pregnancies yielding more than one birth (ie, twins or more), only the birth record for the firstborn infant was extracted. Each entry therefore represents one pregnancy. As women may have had more than one pregnancy during the study period, the same woman may be represented in the data set multiple times. Variables used in this analysis were year of delivery, maternal age at delivery (categorised into age groups of $\leq 24$ years, 25-29, $30-34,35-39, \geq 40$ years), parity, diabetes status (GDM, preexisting maternal diabetes not further specified, no diabetes), maternal Aboriginal and Torres Strait Islander (ie, Indigenous) status and maternal country of birth. Maternal country of birth was reclassified into geographically-based regions using the Australian Bureau of Statistics' Standard Australian Classification of Countries. This classification scheme includes Australia in the group Oceania and Antarctica. However, we categorised Australian-born women separately into two additional groups: Australian-born Indigenous and Australian-born non-Indigenous.

Maternal diabetes status was assigned based on whether the clinician completing the notification form ticked the checkboxes for GDM or pre-existing maternal diabetes. Recording of GDM and pre-existing diabetes in the VPDC are reported to be $99.4 \%$ and $99.8 \%$ accurate, respectively. ${ }^{35}$ Over the study period, Australian guidelines recommended universal offer of GDM screening, with selective screening of high-risk women considered appropriate in resource limited or low prevalence 
settings. Screening is performed at 26-28 weeks gestation and a positive result is a $1 \mathrm{~h}$ venous plasma glucose level of $\geq 7.8 \mathrm{mmol} / \mathrm{L}$ after a morning, non-fasting $50 \mathrm{~g}$ glucose load or $\geq 8 \mathrm{mmol} / \mathrm{L}$ after a morning, non-fasting $75 \mathrm{~g}$ glucose load. Confirmation of GDM diagnosis after a positive screening test requires an OGTT at 2630 weeks gestation with venous plasma glucose levels of $\geq 5.5 \mathrm{mmol} / \mathrm{L}$ at $0 \mathrm{~h}$ and $/$ or $\geq 8 \mathrm{mmol} / \mathrm{L}$ at $2 \mathrm{~h} .{ }^{5}$

\section{Statistical analyses}

Maternal demographic characteristics over time were examined using descriptive statistics. Crude and age-standardised annual prevalence rates of pre-existing diabetes, GDM and all diabetes were calculated as a percentage of total annual pregnancies, using direct standardisation to the maternal age structure of the entire study population. GDM prevalence rates over time were further examined by maternal age group and region of birth. Small numbers precluded similar analyses for preexisting diabetes. To examine the effect of denominator variation on overall GDM prevalence estimates, annual GDM prevalence rates were also calculated after excluding from the denominator pregnancies in women with pre-existing diabetes.

Women who had more than one pregnancy during the study period were included in each year that they delivered. This approach, coupled with the fact that having diabetes of any form in pregnancy increases the likelihood of diabetes in subsequent pregnancies, meant that observations were not necessarily independent. As the assumption of independence that underlies tests for linear trend was not fulfilled, such analyses were not performed, and age-standardised prevalence rates were considered significantly different if $95 \%$ CIs did not overlap. For sensitivity analysis, annual prevalence rates of pre-existing diabetes, GDM and all diabetes were calculated after restricting to women giving birth for the first time, and tests for linear trend were performed for this subgroup.

Data were analysed using Stata V.11.0. Permission to access and analyse data was granted by the Consultative Council on Obstetric and Paediatric Mortality and Morbidity, Victorian Department of Health. The Flinders University Social and Behavioural Research ethics committee exempted this study from requiring ethics approval, as it involved analysis of existing de-identified data.

\section{RESULTS}

During the 10-year study period, there were 634932 pregnancies resulting in a birth registration with the VPDC (table 1). In 2008 there were 15.7\% more pregnancies than in 1999. Mean maternal age increased from 29.7 years in 1999 to 30.8 years in 2008. The number of births to women aged 40 years and over was 91.3\% higher in 2008 than in 1999.

Maternal region of birth was known for $99.7 \%$ ( $n=632805)$ of pregnancies, of which $74.6 \%$ occurred in Australian-born women of non-Indigenous descent (table 1). There was an overall trend of an increasing number of pregnancies in women born in all regions, with the exception of North-West Europe and Southern and Eastern Europe where there was a decline. The trend of increasing pregnancies was particularly strong in women from Southern and Central Asia (table 1). The number of women becoming pregnant for the first time increased during the study period with 5486 $(22.1 \%)$ more first pregnancies recorded in 2008 compared with 1999 (table 1).

\section{Diabetes in pregnancy}

In $2008,6.1 \%$ of all pregnancies were complicated by some form of diabetes, compared with $4.3 \%$ in 1999 (table 2). Each year, pregnancies occurring in older women (those aged 35-39 years and 40 years or older) had higher prevalence of any form of diabetes than pregnancies in younger women (data not shown).

\section{Prevalence of pre-existing maternal diabetes in pregnancy}

Between 1999 and 2008, 2954 pregnancies (0.5\%) occurred in women with known pre-existing diabetes. The prevalence rate of pre-existing diabetes increased from $0.4 \%$ to $0.6 \%$, representing an increase of $50 \%$ over the study period and there was little difference between the crude and age-standardised estimates (figure 1A). The absolute annual number of pregnancies in women with pre-existing diabetes almost doubled over this period.

For the entire 10-year period, the greatest absolute number of pregnancies in women with pre-existing diabetes occurred in Australian-born non-Indigenous women, and for the migrant groups, in those born in South-East Asia and Southern and Central Asia; preexisting diabetes prevalence rates were however highest in pregnancies among women born in Southern and Central Asia and Sub-Saharan Africa (data not shown).

\section{Prevalence of GDM}

Of all pregnancies in Victoria from 1999 to 2008, 29147 $(4.6 \%)$ were complicated by GDM. Overall, the annual number of GDM pregnancies increased by $64 \%$ between 1999 and 2008. Increases in the absolute number of GDM pregnancies over time were apparent in all but the youngest group of women (figure 1B). GDM also increased as a proportion of total pregnancies, such that in 2008, the age-standardised GDM prevalence rate was $31 \%$ higher than in 1999 (table 2). Over the study period, crude GDM prevalence rates tended to increase in pregnancies among women in most age groups (figure 1C). Analysis of data from women in their first pregnancy who did not have pre-existing diabetes revealed a significant positive linear trend in the prevalence of the crude $(\mathrm{p}<0.001)$ and age-standardised $(p<0.001)$ rates of GDM over the study period.

Considerable differences in GDM prevalence rates existed by maternal region of birth (figure 2). Prevalence increased over time, both among Australian- 
Table 1 Maternal demographic characteristics for pregnancies yielding births notified to the Victorian Perinatal Data Collection by year of delivery, Victoria $1999-2008^{*}$

\begin{tabular}{|c|c|c|c|c|c|c|c|c|c|c|c|}
\hline & \multicolumn{11}{|c|}{ Year of delivery } \\
\hline & 1999 & 2000 & 2001 & 2002 & 2003 & 2004 & 2005 & 2006 & 2007 & 2008 & $\begin{array}{l}\text { Total } \\
\text { 1999-2008 }\end{array}$ \\
\hline \multicolumn{12}{|l|}{ Maternal age group $(\mathrm{N})$} \\
\hline$\leq 24$ years & 9768 & 9363 & 9270 & 9152 & 8903 & 8644 & 8895 & 9445 & 9619 & 9762 & 92821 \\
\hline 25-29 years & 19074 & 18537 & 17283 & 16535 & 16241 & 15740 & 16213 & 16739 & 17652 & 17583 & 171597 \\
\hline 30-34 years & 20485 & 20957 & 21667 & 22615 & 23050 & 23119 & 23748 & 24447 & 24475 & 24021 & 228584 \\
\hline $35-39$ years & 9456 & 9839 & 9895 & 10563 & 10796 & 11534 & 12765 & 13859 & 15137 & 15420 & 119264 \\
\hline$\geq 40$ years & 1641 & 1731 & 1879 & 1981 & 2117 & 2241 & 2393 & 2658 & 2854 & 3139 & 22634 \\
\hline Total & 60424 & 60427 & 59994 & 60846 & 61107 & 61278 & 64014 & 67148 & 69737 & 69925 & 634900 \\
\hline Percentage of aged $>30$ & 52.27 & 53.83 & 55.74 & 57.78 & 58.85 & 60.21 & 60.78 & 61.01 & 60.89 & 60.89 & 58.33 \\
\hline \multicolumn{12}{|l|}{ Parity } \\
\hline 1 & 24879 & 25242 & 24662 & 25511 & 26015 & 26328 & 27568 & 29024 & 30066 & 30362 & 269657 \\
\hline 2 or higher & 35545 & 35185 & 35332 & 35335 & 35091 & 34950 & 36446 & 38124 & 39671 & 39563 & 365242 \\
\hline \multicolumn{12}{|l|}{ Region of birth $\dagger$} \\
\hline Australia (non-Indigenous) & 45573 & 45258 & 45236 & 46076 & 46014 & 45985 & 47715 & 49764 & 50342 & 50042 & 472005 \\
\hline Oceania & 1496 & 1488 & 1626 & 1566 & 1663 & 1636 & 1685 & 1838 & 1846 & 1974 & 16818 \\
\hline North-West Europe & 2565 & 2438 & 2353 & 2275 & 2134 & 2127 & 2156 & 2250 & 2400 & 2213 & 22911 \\
\hline Southern and Eastern Europe & 1821 & 1700 & 1595 & 1527 & 1611 & 1440 & 1468 & 1477 & 1562 & 1451 & 15652 \\
\hline North Africa and Middle East & 1630 & 1573 & 1537 & 1581 & 1669 & 1684 & 1889 & 1979 & 1997 & 2146 & 17685 \\
\hline South-East Asia & 3234 & 3667 & 3304 & 3364 & 3506 & 3419 & 3427 & 3598 & 4053 & 4113 & 35685 \\
\hline North-East Asia & 1158 & 1256 & 1080 & 1125 & 1061 & 1122 & 1148 & 1305 & 1691 & 1704 & 12650 \\
\hline Southern and Central Asia & 1125 & 1184 & 1194 & 1228 & 1346 & 1512 & 1793 & 2195 & 2675 & 3251 & 17503 \\
\hline Americas & 651 & 693 & 721 & 734 & 691 & 744 & 806 & 840 & 864 & 846 & 7590 \\
\hline Sub-Saharan Africa & 708 & 765 & 863 & 854 & 905 & 990 & 1152 & 1145 & 1260 & 1248 & 9890 \\
\hline Australia (Indigenous) & 397 & 325 & 358 & 366 & 326 & 394 & 463 & 501 & 628 & 658 & 4416 \\
\hline
\end{tabular}

$397 \quad 325$

358

366

*Includes women who had more than one pregnancy during the study period; 32 births had

tOf the 634932 registered births 2127 recorded the maternal region of birth as unknown. 
Table 2 Crude and age-standardised prevalence of GDM by year of delivery and denominator, Victoria 1999-2008

\begin{tabular}{|c|c|c|c|c|c|c|c|c|}
\hline \multirow[b]{2}{*}{ Year } & \multirow[b]{2}{*}{ n (all births) } & \multirow[b]{2}{*}{ n (GDM) } & \multicolumn{2}{|c|}{ GDM/all pregnancies (\%) } & \multicolumn{2}{|c|}{$\begin{array}{l}\text { GDM/all pregnancies less } \\
\text { pre-existing (\%) }\end{array}$} & \multicolumn{2}{|c|}{$\begin{array}{l}\text { All forms of diabetes in } \\
\text { pregnancy (\%) }\end{array}$} \\
\hline & & & Crude & Age-standardised & Crude & Age-standardised $^{\star}$ & Crude & Age-standardised \\
\hline 1999 & 60424 & 2356 & 3.90 & $4.10(3.94-4.26)$ & 3.91 & $4.11(3.95-4.28)$ & 4.27 & $4.48(4.31-4.65)$ \\
\hline 2000 & 60431 & 2548 & 4.22 & 4.38 (4.21-4.55) & 4.23 & 4.39 (4.23-4.56) & 4.56 & $4.73(4.56-4.90)$ \\
\hline 2001 & 59997 & 2593 & 4.32 & $4.43(4.26-4.60)$ & 4.34 & $4.45(4.28-4.61)$ & 4.71 & $4.82(4.65-5.00)$ \\
\hline 2002 & 60847 & 2752 & 4.52 & $4.58(4.41-4.74)$ & 4.54 & $4.59(4.43-4.76)$ & 4.95 & $5.00(4.83-5.18)$ \\
\hline 2003 & 61111 & 2611 & 4.27 & $4.29(4.13-4.46)$ & 4.29 & $4.31(4.15-4.47)$ & 4.71 & $4.73(4.56-4.90)$ \\
\hline 2004 & 61283 & 2547 & 4.16 & 4.13 (3.97-4.29) & 4.17 & $4.15(3.99-4.31)$ & 4.61 & $4.58(4.42-4.75)$ \\
\hline 2005 & 64022 & 3027 & 4.73 & $4.66(4.50-4.83)$ & 4.75 & $4.69(4.52-4.85)$ & 5.24 & $5.17(5.00-5.34)$ \\
\hline 2006 & 67150 & 3295 & 4.91 & 4.82 (4.66-4.98) & 4.93 & $4.85(4.69-5.01)$ & 5.43 & $5.34(5.17-5.51)$ \\
\hline 2007 & 69738 & 3559 & 5.10 & $4.98(4.82-5.14)$ & 5.13 & $5.01(4.85-5.17)$ & 5.67 & $5.53(5.37-5.70)$ \\
\hline 2008 & 69929 & 3859 & 5.52 & $5.37(5.21-5.54)$ & 5.55 & $5.40(5.24-5.57)$ & 6.12 & $5.96(5.78-6.13)$ \\
\hline
\end{tabular}

born non-Indigenous women and overseas-born women considered collectively. However, the same pattern was not evident when considering Indigenous Australians and each migrant group individually. The extent of the changes in GDM prevalence rates over time varied by migrant origin status. In Australian-born non-Indigenous women, age-standardised GDM prevalence in 2007 and 2008 was $29 \%$ higher than in 1999 and 2000 (4\% vs $3.1 \%$ ), whereas among all overseas-born women collectively, prevalence increased by $12.3 \%$ between these two time periods $(8.2 \%$ vs $7.3 \%$; figure 2$)$ with differences between the various groups.

\section{Effect of denominator variation}

Including or excluding women with pre-existing diabetes had little effect on GDM prevalence rates overall (table 2). Estimates were generally similar, albeit lower, when considering only women in their first pregnancy (see online supplementary table S1). Including or excluding women with pre-existing diabetes also had very little effect on GDM prevalence rates by maternal region of birth (data not shown).

\section{DISCUSSION}

Prevalence of both pre-existing diabetes in pregnancy and GDM increased in Victoria, Australia over the period 1999-2008. The number of births to older mothers increased over the study period, almost doubling for those aged 40 years and over. However, age-standardising had little effect on prevalence rates, and GDM prevalence increased within most maternal age groups, indicating that rising maternal age does not fully explain the upward trends. GDM prevalence increased to a greater extent in pregnancies among Australian-born non-Indigenous women compared with rates in all overseas-born women. Consistent with existing knowledge, ${ }^{20} 22 \quad 232^{28-31}$ pregnancies occurring in women born throughout Asia and in North Africa and the Middle East had the highest GDM rates.
Similar to recent reports of rising trends in GDM burden nationally ${ }^{20}$ and in the multiethnic state of New South Wales, ${ }^{3} 23$ we noted a pronounced increase in overall GDM prevalence in Victoria from 1999 to 2008. This may reflect secular increases in obesity prevalence in the general population ${ }^{36}$; effects of obesity could not be examined as maternal pre-pregnancy body mass index (BMI) was not recorded in the VPDC during the study period. BMI trend data in Australian obstetric patients are sparse and generally from single centres. ${ }^{37}$ Maternal BMI has been recorded in the VPDC since 2009; further research is required in the Australian context when population-level obstetric BMI trend data become available.

In our study GDM prevalence increased across most maternal age groups. This and the fact that results were generally similar when restricting to primiparous women indicates that factors other than those examined in this study likely largely account for the observed trends. In the general Australian population, prevalence of overweight/obesity has increased across most age groups over time ${ }^{38}$ and this may be contributing to the rising GDM prevalence observed in our study among most groups including the younger mothers. Rising GDM prevalence may also reflect increases in pre-existing but previously undiagnosed diabetes; as postnatal OGTT results were not available, the extent to which this is the case cannot be established. Additionally, GDM ascertainment may be influenced by systemic factors, which themselves may change over time. In particular, screening and diagnostic practices and uptake rates will influence case detection. For example, after introduction of universal OGTT testing in a regional hospital in northern Australia, testing rates in Indigenous Australian women increased from $31.4 \%$ in 2006 to $65.6 \%$ in 2008 and GDM rates tripled. ${ }^{26}$

This study has demonstrated that migrant disparities in GDM prevalence appear to be diminishing, but in a concerning rather than desirable manner: increases in GDM prevalence rates over time were most pronounced in Australian-born non-Indigenous women, among whom 
Figure 1 (A) Crude and age-standardised prevalence of pre-existing maternal diabetes in pregnancy by year of delivery, Victoria 1999-2008; (B) Crude number of GDM cases by year of delivery and maternal age group, Victoria 1999-2008; (C) Crude GDM prevalence rates* by year of delivery and maternal age group, Victoria 1999-2008. *The denominator used to calculate prevalence of GDM is all pregnancies.
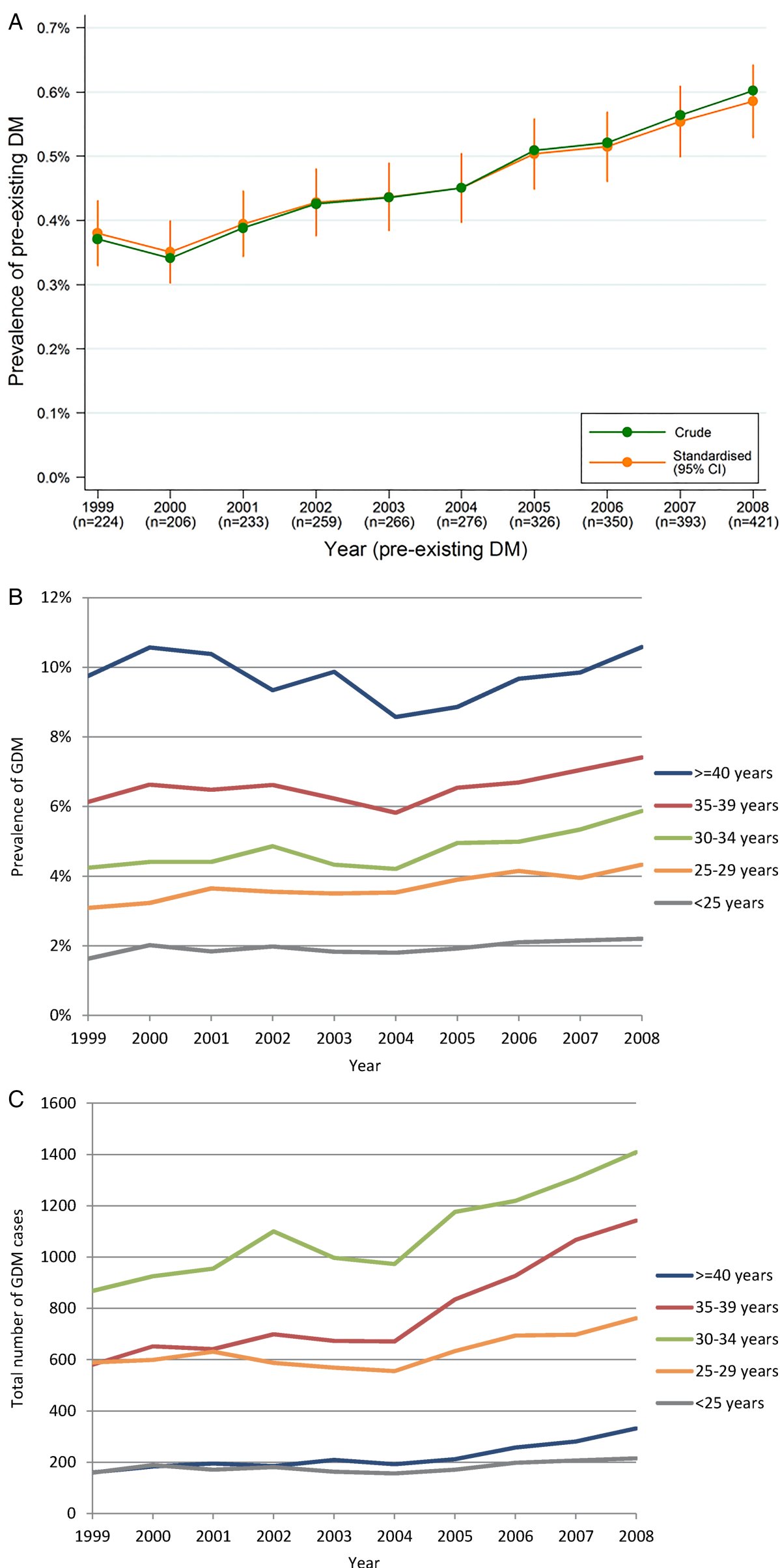


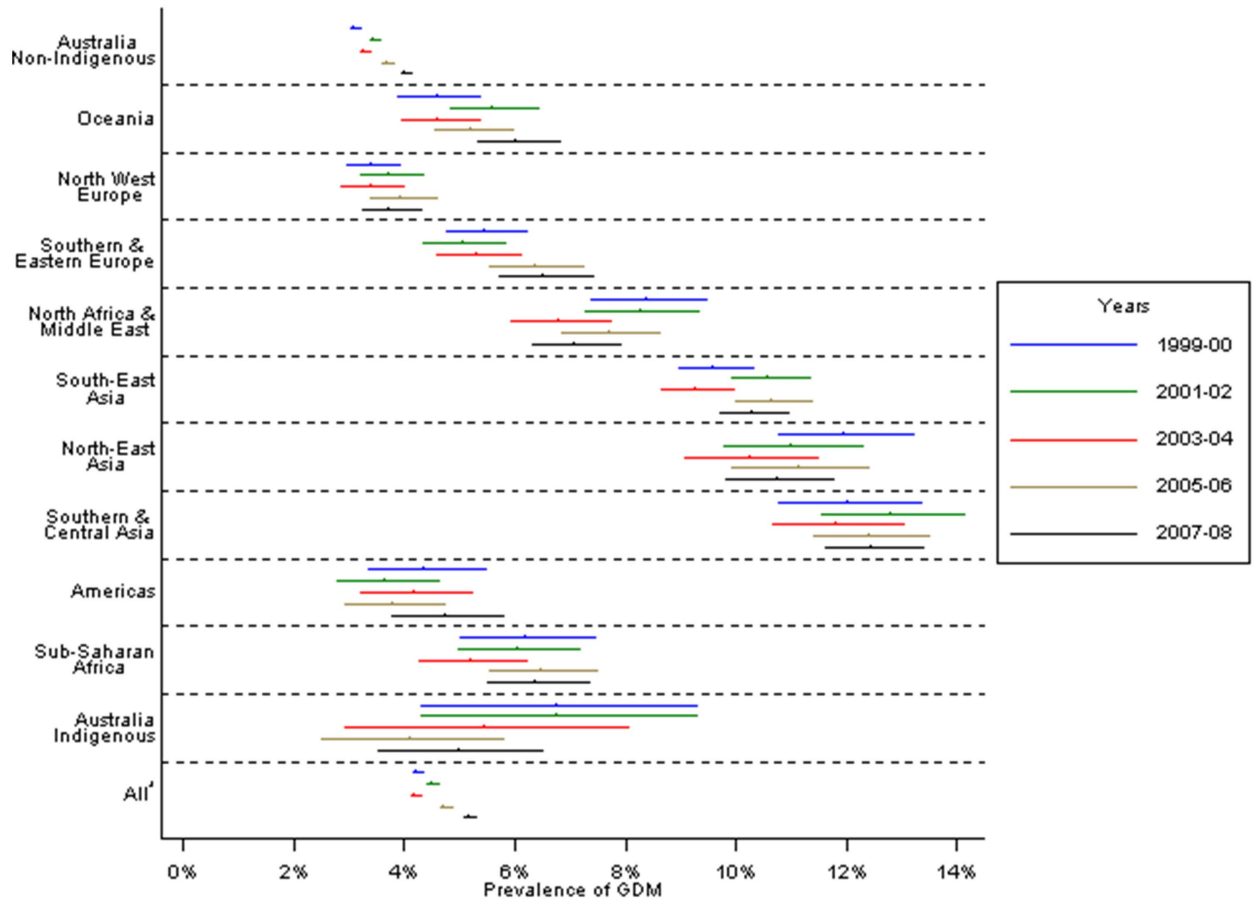

Figure 2 Age-standardised GDM prevalence rates* by maternal region of birth and year of delivery, Victoria 1999-2008. *The denominator used to calculate prevalence of GDM is all pregnancies.

GDM prevalence was converging with the higher rates in overseas-born mothers. A similar phenomenon closing the gap in burden of diabetes in pregnancy between high rate Indigenous and increasingly higher rate non-Indigenous Australian women has also been previously described..$^{20}$ The desired key to reducing overall disease burden and sociocultural inequities is to close the gap by reducing prevalence among high-risk groups and to contain and ideally reduce the prevalence among lower risk groups. Our findings differ from recent national reports that GDM increased to a similar extent among Australian-born (23\% increase) and all overseasborn mothers collectively ( $24 \%$ increase), with differential increases between individual migrant groups, for the period 2000-2001 and 2005-2006. ${ }^{20}$ That GDM burden in Victoria increased over time among all migrant groups collectively but not individually may be due to the fact that the proportion of mothers born in high prevalence regions and giving birth in Victoria has increased over time ${ }^{39}$ but our study may have been underpowered to detect differences within individual migrant groups. Alternatively, it is possible that risk factor distribution or screening uptake may have changed more over time for some groups than others, or that there is a difference in the proportion of diagnosed to undiagnosed diabetes between migrants and local-born women. Future research should seek to confirm our results and investigate underlying causes.

In contrast to earlier findings, ${ }^{3}$ recent work suggests that in the Australian obstetric population, pre-existing type 2 diabetes is now as common as type 1 diabetes, ${ }^{2}$ and even the predominant form of pre-existing diabetes in pregnancy. ${ }^{40}$ The increasing number of pregnancies in women with pre-existing diabetes observed in our study is consistent with international findings ${ }^{7-9} 11 \quad 12$ and reinforces the urgent need for population-level preventive initiatives to address the growing public health problem of diabetes in the young. These upward trends are likely to continue, particularly in the setting of the obesity and type 2 diabetes epidemics in the general population, ${ }^{36}$ evidence of earlier onset of type 2 diabetes, trends toward delayed childbearing ${ }^{39}$ and introduction of new antenatal screening guidelines ${ }^{6}{ }^{32}$ that will increase case detection.

There are a number of strengths to this study. This is one of few papers to report secular trends in Australian population-level prevalence of pre-existing diabetes in pregnancy $^{3}$ and to our knowledge, the only one to present data spanning a decade. It is also one of few Australian studies, and the first from Victoria since the early 1990s, to report ethnospecific secular trends in GDM prevalence. This is important because of Australia's diverse and evolving multiethnic demography. Others have reported their GDM prevalences after excluding pre-existing diabetes as sensitivity analysis ${ }^{19}$ but as far as we are aware, our paper is the first to specifically examine using a single database the effect of including or excluding the growing group of women with pre-existing diabetes on GDM prevalence estimates, in important subgroups such as region of birth where denominator variation plausibly might have an effect. This methodological issue is likely to become increasingly relevant, with implications for service planning and delivery and preventive efforts worldwide. 
The data source was a comprehensive population-level perinatal data collection. Case ascertainment depends on accurate completion of birth report forms-training manuals exist to facilitate this. Data collection forms did not change over the study period, with GDM and preexisting diabetes status recorded consistently using checkboxes; this reduces the likelihood of ascertainment bias over time.

Study limitations should be noted. Australian guidelines over the study period recommended universal screening for GDM, with selective screening to be considered in settings with limited resources or low GDM burden. ${ }^{5}$ As it is not possible to identify unscreened pregnancies in our data, all pregnancies yielding births that were reported to the VPDC during the study period were included in this analysis. Some women may not have been tested for GDM, so our rates are minimum estimates. Screening practice may have varied between clinicians and centres. For example, in 1999 there was considerable variation in GDM testing in Australian hospitals, including differences in the universal versus selective offer of screening and the testing protocols used. ${ }^{41}$ Testing practices within centres may also have changed over time. ${ }^{26}$ To enable identification of screened pregnancies, we suggest that information on diabetes testing status should be collected in perinatal data sets. Finally, the region of birth classifications used in this study were necessarily broad and may mask heterogeneity within and between groups. Women may have been born in Australia but have the behavioural and biological risk factor profiles of their ethnic group of origin; ethnicity data are not captured in the VPDC so it is not possible to ascertain the extent to which this is the case.

In summary, prevalence of both pre-existing diabetes and GDM increased among the Victorian obstetric population between 1999 and 2008 and these increases are not fully explained by rising maternal age. GDM prevalence increased at a greater rate among Australian-born non-Indigenous women than among migrant women. These findings have important implications across all levels of the healthcare system, from the primary prevention sphere to pre-pregnancy counselling and antenatal clinical service provision, through to postnatal management of both mother and infant and tertiary prevention and monitoring. As such, these results have clear implications for clinicians, who need to be aware of the sociocultural distribution of GDM and actively managing women at risk. This information is also important for policymakers and the public health profession, both to guide preventive initiatives and to facilitate health service planning in the face of an increasing morbidity burden for mothers and offspring as prevalence of GDM and preexisting diabetes increase. Given the health risks conferred on infants of pregnancies complicated by diabetes, addressing the rising burden of diabetes of any form in pregnancy is essential if we are to break the cycle of intergenerational diabetes transmission and reverse the direction and slope of trend graphs in future.
Finally, there has been debate surrounding many aspects of GDM epidemiology, but the issue of denominator variation is one that appears to have been overlooked, yet warrants consideration. Although having negligible effect in our data set given low rates of preexisting diabetes, to include pre-existing diabetes in the denominator could potentially underestimate GDM prevalence; to exclude pre-existing cases could underestimate the total burden of diabetes in pregnancy. These issues should come to the attention of expert groups: a consistent approach is required, in order to accurately gauge disease burden, compare prevalence within and between populations, and monitor trends. Perhaps the best approach is to report prevalence of both GDM and pre-existing diabetes separately. Particularly given the looming rise in diagnosed cases of pre-existing disease, measurement methodology will increasingly matter.

\section{Author affiliations}

${ }^{1}$ Greater Green Triangle University Department of Rural Health, Flinders and Deakin Universities, Warrnambool, Victoria, Australia

${ }^{2}$ Department of Epidemiology and Preventive Medicine, Monash University, Melbourne, Victoria, Australia

${ }^{3}$ Department of Medicine, Northwest Academic Centre, The University of Melbourne and Western Health, Melbourne, Victoria, Australia

${ }^{4}$ Consultative Council on Obstetric and Paediatric Mortality and Morbidity, Clinical Councils Unit, Department of Health, Melbourne, Victoria, Australia

${ }^{5}$ Judith Lumley Centre, La Trobe University, Melbourne, Victoria, Australia

${ }^{6}$ Melbourne School of Population and Global Health, The University of Melbourne, Melbourne, Victoria, Australia

Contributors MA conceived and designed the study, assisted with data analysis and interpretation, wrote and edited manuscript. VLV analysed and interpreted data, edited manuscript. EDJ designed the study and edited manuscript. M-AD designed the study, analysed and interpreted data, edited manuscript. BP conceived and designed the study, analysed and interpreted data. J0 edited the manuscript. JAD conceived and designed the study, edited manuscript, supervised the study and is the guarantor.

Funding This research received no specific grant from any funding agency in the public, commercial or not-for-profit sectors.

\section{Competing interests None.}

Provenance and peer review Not commissioned; externally peer reviewed.

Data sharing statement The statistical code used to generate the results in this article is available from the corresponding author on request. The custodian of the data set used in this article is the Consultative Council on Obstetric and Paediatric Mortality and Morbidity (CCOPMM). All enquiries to access this data set should be directed to CCOPMM.

Open Access This is an Open Access article distributed in accordance with the Creative Commons Attribution Non Commercial (CC BY-NC 4.0) license, which permits others to distribute, remix, adapt, build upon this work noncommercially, and license their derivative works on different terms, provided the original work is properly cited and the use is non-commercial. See: http:// creativecommons.org/licenses/by-nc/4.0/

\section{REFERENCES}

1. Hodson K, Robson S, Taylor R. Gestational diabetes: emerging concepts in pathophysiology. Obstet Med 2010;3:128-32.

2. Australian Institute of Health and Welfare. Diabetes in pregnancy: its impact on Australian women and their babies. Diabetes series no. 14. Cat. no. CVD 52. Canberra: AIHW, 2010.

3. Shand AW, Bell JC, McElduff A, et al. Outcomes of pregnancies in women with pre-gestational diabetes mellitus and gestational diabetes mellitus; a population-based study in New South Wales, Australia, 1998-2002. Diabet Med 2008;25:708-15. 
4. McElduff A, Cheung NW, McIntyre HD, et al. The Australasian Diabetes in Pregnancy Society consensus guidelines for the management of type 1 and type 2 diabetes in relation to pregnancy. Med J Aust 2005;183:373-7.

5. Hoffman L, Nolan C, Wilson JD, et al. Gestational diabetes mellitus -management guidelines. The Australasian Diabetes in Pregnancy Society. Med J Aust 1998;169:93-7.

6. Nankervis A, McIntyre HD, Moses R, et al. Australasian Diabetes in Pregnancy Society (ADIPS) consensus guidelines for the testing and diagnosis of gestational diabetes mellitus in Australia. 2013; Version 2:3/5/13

7. Lawrence JM, Contreras R, Chen W, et al. Trends in the prevalence of preexisting diabetes and gestational diabetes mellitus among a racially/ethnically diverse population of pregnant women, 19992005. Diabetes Care 2008:31:899-904.

8. Bell R, Bailey K, Cresswell T, et al. Trends in prevalence and outcomes of pregnancy in women with pre-existing type I and type II diabetes. BJOG 2008;115:445-52.

9. Thorpe LE, Berger D, Ellis JA, et al. Trends and racial/ethnic disparities in gestational diabetes among pregnant women in New York City, 1990-2001. Am J Public Health 2005;95:1536-9.

10. Falhammar H, Davis B, Bond D, et al. Maternal and neonatal outcomes in the Torres Strait Islands with a sixfold increase in type 2 diabetes in pregnancy over six years. Aust N Z J Obstet Gynaecol 2010;50:120-6.

11. Feig DS, Hwee J, Shah BR, et al. Trends in incidence of diabetes in pregnancy and serious perinatal outcomes: a large, population-based study in Ontario, Canada, 1996-2010. Diabetes Care 2014;37:1590-6.

12. Albrecht SS, Kuklina EV, Bansil P, et al. Diabetes trends among delivery hospitalisations in the US, 1994-2004. Diabetes Care 2010;33:768-73.

13. Aljohani N, Rempel BM, Ludwig S, et al. Gestational diabetes in Manitoba during a twenty-year period. Clin Invest Med 2008;31: E131-E7.

14. Zhang F, Dong L, Zhang CP, et al. Increasing prevalence of gestational diabetes mellitus in Chinese women from 1999 to 2008. Diabet Med 2011;28:652-7.

15. Rajab KE, Issa AA, Hasan ZA, et al. Incidence of gestational diabetes mellitus in Bahrain from 2002 to 2010. Int J Gynecol Obstet 2012;117:74-7.

16. Getahun D, Nath C, Ananth CV, et al. Gestational diabetes in the United States: temporal trends 1989 through 2004. Am J Obstet Gynecol 2008;198:525.e1-5.

17. Lu GC, Rouse DJ, DuBard M, et al. The effect of the increasing prevalence of maternal obesity on perinatal morbidity. $J$ Obstet Gynaecol 2001;185:845-9.

18. Ferrara A, Kahn HS, Quesenberry CP, et al. An increase in the incidence of gestational diabetes mellitus: Northern California, 1991-2000. Obstet Gynecol 2004;103:526-33.

19. Wang Y, Chen L, Xiao K, et al. Increasing incidence of gestational diabetes mellitus in Louisiana, 1997-2009. J Womens Health (Larchmt) 2012;21:319-25.

20. Templeton M, Pieris-Caldwell I. Gestational diabetes mellitus in Australia, 2005-06. Diabetes series no. 10. Cat. no. CVD 44 Canberra: AlHW, 2008.

21. Henry OA, Beischer NA, Sheedy MT, et al. Gestational diabetes and follow-up among immigrant Vietnam-born women. Aust N Z J Obstet Gynaecol 1993;33:109-14.

22. Beischer NA, Oats JN, Henry OA, et al. Incidence and severity of gestational diabetes mellitus according to country of birth in women living in Australia. Diabetes 1991;2:35-8.
23. Anna V, van der Ploeg HP, Wah Cheung N, et al. Sociodemographic correlates of the increasing trend in prevalence of gestational diabetes mellitus in a large population of women between 1995 and 2005. Diabetes Care 2008;31:2288-93.

24. Ishak M, Petocz P. Gestational diabetes among Aboriginal Australians: prevalence, time trend and comparisons with non-Aboriginal Australians. Ethn Dis 2003;13:55-60.

25. Kim SY, Humphrey MD. Decrease in incidence of gestational diabetes mellitus in Far North Queensland between 1992 and 1996. Aust N Z J Obstet Gynaecol 1999;39:40-3.

26. Davis $B$, McLean A, Sinha AK, et al. A threefold increase in gestational diabetes over two years: review of screening practices and pregnancy outcomes in Indigenous women of Cape York, Australia. Aust NZJ Obstet Gynaecol 2013;53:363-8.

27. Ferrara A. Increasing prevalence of gestational diabetes mellitus. A public health perspective. Diabetes Care 2007;30(S2):S141-S6.

28. Carolan M, Davey M-A, Biro MA, et al. Maternal age, ethnicity and gestational diabetes mellitus. Midwifery 2012;28:778-83.

29. Stone CA, McLachlan KA, Halliday JL, et al. Gestational diabetes in Victoria in 1996: incidence, risk factors and outcomes. Med J Aust 2002;177:486-91.

30. Teh WT, Teede HJ, Paul E, et al. Risk factors for gestational diabetes mellitus: Implications for the application of screening guidelines. Aust N Z J Obstet Gynaecol 2011;51:26-30.

31. Moses RG, Griffiths RD, McPherson $S$. The incidence of gestational diabetes mellitus in the Illawarra area of New South Wales. Aust NZ J Obstet Gynaecol 1994;34:425-7.

32. Metzger BE, Gabbe SG, Persson B, et al. International Association of Diabetes in Pregnancy Study Groups Consensus Panel. International Association of Diabetes and Pregnancy Study Groups recommendations on the diagnosis and classification of hyperglycemia in pregnancy. Diabetes Care 2010;33:676-82.

33. Moses RG, Morris GJ, Petocz P, et al. The impact of potential new diagnostic criteria on the prevalence of gestational diabetes mellitus in Australia. Med J Aust 2011:194:338-40.

34. Mclntyre HD. Diagnosing gestational diabetes mellitus: rationed or rationally related to risk? Diabetes Care 2013;36:2879-80.

35. Davey M-A, Sloan M-L, Palma S, et al. Methodological processes in validating and analysing the quality of population-based data: a case study using the Victorian Perinatal Data Collection. HIM J 2013;42:12-19.

36. Department of Health 2011. Victorian population health survey. Melbourne: State Government of Victoria, 2009. http://www.health. vic.gov.au/healthstatus/survey/vphs2009.htm

37. Mclntyre HD, Gibbons KS, Flenady VJ, et al. Overweight and obesity in Australian mothers: epidemic or endemic? Med J Aust 2012;196:184-8.

38. Australian Institute of Health and Welfare. Risk factor trends: age patterns in key health risks over time. Cat. no. PHE 166. Canberra: AlHW, 2012.

39. Consultative Council on Obstetric and Paediatric Mortality and Morbidity. Births in Victoria 2007 and 2008. Melbourne: Department of Health, 2010

40. McElduff A, Ross GP, Lagstrom JA, et al. Pregestational diabetes and pregnancy. An Australian experience. Diabetes Care 2005;28:1260.

41. Rumbold AR, Crowther CA. Guideline use for gestational diabetes mellitus and current screening, diagnositic and management practices in Australian hospitals. Aust NZ J Obstet Gynaecol 2001;41:86-90. 